веннонаучным дисциплинам в техническом вузе: автореф. дис. ... д-ра пед. наук: 13.00.08. СПб., 2001. 34 с.

23. Бордовский Г.А. Современные проблемы совершенствования образовательного процесса в педагогических вузах. СПб.: Изд-во РГПУ им. А.И. Герцена, 1997. $85 \mathrm{c}$.

24. Садовников Н.В. Связь фундаментализации с целями образования // Интеграция образования. 2004. № 3. С. 81-84.

25. Всемирные стандарты WFME по повышению качества медицинского образования // Сибирское медицинское обозрение. 2011. № 3 (69). С. 112-115.

26. Каган М.С. Философия культуры. СПб.: Петрополис, $1996.415 \mathrm{c}$.
27. Мамзин А.С. Биология в системе культуры. СПб.: Лань, 1998. 156 с.

28. Гречаный В.В., Сержантов В.Ф. Человек как предмет философского естественнонаучного познания. Л.: Изд. ЛГУ, 1980. 216 с.

29. Мирзоян Э.Н. О некоторых тенденциях развития биологии в XX веке // Историко-биологические исследования. Вып. 7. М.: Наука, 1978. С. 3-24.

30. Гринберг М.П., Архипов А.Н., Кузнецова Т.А. Коммуникативная компетентность врача. Симуляционное обучение. Методика «стандартизированный пациент». М.: Литтера, 2015. 176 с.

31. Залесский Г.Е. Психология мировоззрения и убеждений личности. М.: МГУ, 1994. С. 114-129.

\title{
FUNDAMENTAL TRAINING OF DOCTORS IN ADDITIONAL VOCATIONAL EDUCATION
}

\section{(C) 2018}

Astanina Svetlana Yurievna, candidate of pedagogical sciences, professor of Medical Pedagogy, Philosophy

and Foreign Languages Department, head of Scientific, Methodological and Educational Activities Department Russian Medical Academy of Continuing Professional Education (Moscow, Russian Federation)

Abstract. The paper presents methodology of doctors' fundamental training in additional vocational education. The analysis of trends (humanization, standardization, informatization, integration, ecologization and fundamentalization) of doctors' biological training development in continuous medical education has made it possible to determine how to improve physicians' biological training in the aspect of solving the research problem - to determine methodology of doctors' fundamental training in additional vocational education. The tendency of informatization of doctors' biological training is determined by intensive development of biological sciences, as well as the widespread introduction of theoretical and technological approaches into medical practice. Integration as a trend determines modernization of goals, content, forms, methods of physicians' biological training in the aspect of enhancing the interrelation and interdependent integrity of physicians' biological and special training. The necessity of ecological regularities understanding and scientifically grounded attitude to nature requires systemic doctors' biological training and dictates introducing a wide range of biological and ecological disciplines into doctors' training and development program. These disciplines can help to understand the place of man in the environment and the biosphere as a whole from the standpoint of biocentric and polycentric approaches. Fundamentalization as a tendency for physicians' biological training development requires training construction on the basis of a conceptual presentation of the educational content that contributes to the deepening of theoretical, scientific and vocational training of trainees and the expansion of their vocational training profile. Standardization defines requirements for physicians training level in biological disciplines (anatomy, physiology, biochemistry, immunology, genetics, etc.) of all medical specialties as well as requirements for medical personnel ecological literacy increasing. The tendency of humanization manifests itself in openness, in understanding the social role of a person in improving doctors' professional competencies, contributes to imparting a personal meaning to the acquired knowledge and determines the preservation of the individual identity.

Keywords: fundamental training of doctors; additional vocational education; biological training; trends of doctors' biological training development; humanization; informatization; integration; fundamentalization; ecologization; standardization; labor functions; professional tasks.

УДК 378.14.014.13; 378.046.4

Статья поступила в редакцию 28.04.2018

\section{ГОТОВНОСТЬ К МЕДИАЦИИ КАК КОМПЕТЕНЦИЯ БАКАЛАВРОВ ГУМАНИТАРНЫХ НАПРАВЛЕНИЙ}

(C) 2018

Бударина Анна Олеговна, доктор педагогических наук, профессор, директор Педагогического института

Симаева Ирина Николаевна, доктор психологических наук, профессор Института гуманитарных наук

Чуприс Алина Сергеевна, аспирант Педагогического института

Шахторина Екатерина Валентиновна, кандидат педагогических наук, доцент Института гуманитарных наук

Балтийский федеральный университет имени Иммануила Канта (г. Калининград, Российская Федерация)

Аннотаџия. Авторы анализируют ряд взаимосвязанных проблем социального, методологического и методического характера, которые препятствуют развитию медиации как профессиональной деятельности в России, и выдвигают идею интегрированного обучения медиации студентов гуманитарных и образовательных направлений бакалавриата на основе компетентностного подхода. Показано, что данный вариативный либо факультативный модуль дает возможность с минимальными затратами подготовить профессиональных медиаторов, имеющих гуманитарное мировоззрение и готовых осуществлять медиацию как социально-гуманитарную практику. Тем самым устраняется рассогласование между объективной потребностью государства и 
общества в медиаторах, узкоутилитарной трактовкой медиатора как посредника в урегулировании споров и конфликтов, размытыми требованиями профессионального стандарта к высшему образованию медиатора и неиспользованием для медиации кадровых ресурсов из числа выпускников бакалавриата. Предлагается ввести в ФГОС $3++$ профессиональной подготовки студентов по гуманитарным и образовательным направлениям универсальную компетенцию «способность и готовность к медиации». Рассмотрена структура данной компетенции и содержание когнитивного, эмоционально-оценочного и побудительного компонентов готовности к профессиональной деятельности в области медиации. Представлены результаты апробации факультативной программы «Основы медиации» и методики моделирования готовности к медиации слушателей факультатива на основе компетентностного подхода, теории аттитюда и идей восстановительного способа реагирования на конфликтные и криминальные ситуации.

Ключевые слова: медиация; гуманитарное мировоззрение; антирепрессивная философия и методология медиации; снижение социальной напряженности; социально-гуманитарные практики; профессиональный стандарт медиатора; компетентностный подход; компетенция; готовность к медиации; дополнительная профессиональная подготовка; компетентность бакалавра; гуманитарные направления высшего образования.

Медиация - сравнительно новый для России вид профессиональной деятельности, происхождение которого обусловлено социально-политической трансформацией, демократизацией общества и внедрением в РФ международной практики решения социальных проблем [1, с. 30-50]. Медиация признана во многих странах Европы и Азии, США эффективной социальной технологией для снижения уровня криминализации подростков и молодежи [2, с. 52-54; 3 , c. $36-48 ; 4$, с. 221$]$, восстановления семейных отношений [5, с. 105-107; 6, с. 452-457]; урегулирования трудовых споров и конфликтов [7, с. 18-21] при одновременном ослаблении репрессивных мер и восстановительным способом реагирования против преступности. Медиация служит действенным методом профилактики этнических и межличностных конфликтов в системе образования [8, с. $219 ; 9$, с. 59 63], совершенствования коммуникации в иноязычной среде $[10$, с. $141 ; 11$, с. 89-114].

На современном этапе развития общества медиация нашла более масштабное приложение в механизме управления социальными процессами [12, c. 170-175], так как рассматривается как ведущий метод урегулирования межнациональных конфликтов и противодействия терроризму [13, с. 284-288]. Несмотря на ряд проблем, обозначились твердые тенденции применения медиации в качестве политической технологии $[14$, с. 90$]$, в том числе в сфере внешнеэкономической деятельности $[15$, с. 5$]$. Медиация рассматривается и как междисциплинарный метод устойчивого развития регионов [16, с. 36].

В основу медиации положены превентивный и восстановительный принципы реагирования на правонарушение, принципы партисипации в организации и планировании конструктивного взаимодействия в конфликте $[17$, с. $108-123]$. Однако становлению и развитию профессиональной деятельности медиаторов в нашей стране препятствует ряд взаимосвязанных проблем социального, методологического и методического характера. Во-первых, медиация предполагает наличие у профессионала гуманитарного мировоззрения и владения социально-гуманитарными практиками, а у участников медиации осознания ответственности за разрешение криминальной или конфликтной ситуации. Тогда как в российской практике медиацию часто осуществляют специалисты права, которым другие участники традиционно пытаются делегировать ответственность [18, с. 108-113]. Следует учитывать и то, что профессиональное мировоззрение юристов базируется на репрессивно-карательном реагировании (наказании), что противоречит идеологии и методологии медиации. В системе образования распространена тенденция вменять обязанности медиатора педагогам-психологам, которые являются членами педагогического коллектива, априори не могут выступать в роли независимого посредника и не обладают необходимыми компетенциями.

Во-вторых, распространено узкоутилитарное понимание и применение деятельности медиаторов лишь для разрешения конфликтных ситуаций в межличностных отношениях, трудовых спорах и т.д. Остаются вне понимания антирепрессивная философия и методология, роль медиации в снижении социальной напряженности в условиях социально-экономического расслоения и поляризации доходов населения, поликультурном и мультинациональном пространстве. Недооценена медиация в системе социально-педагогической профилактики семейного насилия, а также преступности несовершеннолетних, в частности - в условиях системы образования.

Проблема методически отягощается тем, что современная профессиональная подготовка медиаторов регламентирована ФЗ о медиации (2010, с изменениями и дополнениями 2017,2018 ) и Профессиональным стандартом специалиста в области медиации (2014) [19], которые установили только самые общие рамки требований к специалисту-медиатору и не раскрыли сущность компетенций, необходимых для данной профессиональной деятельности. Так, Профессиональный стандарт трактует медиацию ограниченно как урегулирование споров с помощью специальной процедуры с участием в качестве посредника независимого медиатора - специалиста в области права или социальных проблем с соответствующей профессиональной подготовкой Данная альтернатива требований к квалификации проецируется на два аспекта требований к необходимым знаниям и умениям для выполнения функций медиатора - знание основ гражданского, семейного, трудового права, с одной стороны, и основ социальной, когнитивной, гуманистической психологии, а также умения ведения переговоров и социально-психологической коррекции - с другой. Однако знаниевый подход не отражает другие составляющие готовности к профессиональной деятельности медиатора: профессиональное мировоззрение, владение методами разрешения противоречий между ценностями участников процесса, оценки значения ситуации для обеспечения превентивных социальных функций медиации и т.д. 
Релевантной методологической основой для повышения качества и практической направленности профессионального образования в области медиации является компетентностный подход. Компетентностный подход дает возможность определять квалификационные требования к медиатору через понятие компетенций, раскрывать их структуру, устанавливать индикаторы владения компетенциями и оценивать готовность к данному виду профессиональной деятельности в целом и тем самым уточнить некоторые положения профессионального стандарта медиатора $[20 ; 21$, с. $62-67 ; 22]$. Реализации компетентностного подхода к подготовке медиаторов благоприятствуют структурный и вариативный потенциал современных Федеральных государственных образовательных стандартов по гуманитарным направлениям (психология, социология, лингвистика, журналистика, социальная работа и др.) и направлению «Образование и педагогические науки». Элективный модульный формат интегрированного факультативного либо дополнительного обучения студентов разных направлений создает возможность формирования профессионального гуманитарного мировоззрения, основанного на понимании социальных, политических и экономических процессов в поликультурном и мультинациональном пространстве, в частности условий и факторов криминализации подростков и молодежи, распространения агрессии и недоверия в разных социальных группах. Результатом могут стать универсальные и некоторые профессиональные компетенции, в том числе ряд коммуникативных компетенций, предусмотренных ФГОС для различных направлений и сфер профессиональной деятельности. Представляется, что ценностно-мировоззренческий базис выпускников гуманитарных направлений изначально дает им преимущество при дополнительной профессиональной подготовке осуществлять профессиональную деятельность медиатора в самых различных областях.

Идея интегрированного факультативного либо дополнительного обучения медиации позволяет устранить рассогласования между объективной потребностью государства и общества в профессиональных медиаторах, имеющих гуманитарное мировоззрение и готовых осуществлять медиацию как социальногуманитарную практику, узкоутилитарной трактовкой функций, знаний и умений медиатора как посредника в урегулировании споров и конфликтов безотносительно к его профессиональной позиции, неопределенным требованием профессионального стандарта к высшему образованию медиатора и не использованием имеющихся ресурсов в профессиональной подготовке студентов по гуманитарным направлениям.

Реализация данной идеи позволяет без дополнительных затрат на профессиональную подготовку создать потенциальный кадровый ресурс медиаторов из числа выпускников гуманитарных направлений. Однако претворение ее в жизнь до некоторых пор осложнялось ввиду отсутствия методического обеспечения для дополнительной (факультативной) программы профессиональной подготовки и необходимостью разработки более широкого понимания медиации как гуманитарной практики в процессе профессиональной деятельности гуманитарных направлений [23, с. 119-123].
Более пяти лет назад в БФУ им. И. Канта введен факультатив для студентов гуманитарных и образовательных направлений подготовки, целью которого стало формирование у них готовности к профессиональной деятельности медиатора. Программа и методика компетентностного моделирования готовности к медиации опирается на положения компетентностного подхода, теорию аттитюда и идеи восстановительного способа реагирования на конфликтные и криминальные ситуации для развития у обучающихся способности и готовности к медиации.

Мы исходили из положения о том, что готовность к медиации может стать неспецифической универсальной компетенцией в составе профессиональной компетентности представителей гуманитарных профессий. Она формируется в процессе факультативного дополнительного профессионального образования у студентов разных направлений, в частности психологов, педагогов, лингвистов, филологов, журналистов.

Паспорт и структура данной компетенции базируются на компетентностном обосновании содержания образовательной программы с учетом требований Профессионального стандарта и нацелены на формирование у студентов когнитивного, эмоционально-оценочного, конативного компонентов готовности и опыта медиации. Когнитивный компонент компетентностной модели готовности к медиации включает в себя знания, понимание, способность к анализу, синтезу информации о процессе медиации, способности к распознаванию и прогнозированию эмоциональных состояний участников медиации. Создание эмоционально-оценочного компонента готовности охватывает вырабатывание способности к оценке значимости и ценности медиации для конкретной цели, ценностной ориентации на антирепрессивный характер взаимодействия и соучастие в процессе примирения. Формирование побудительного компонента готовности к медиации включает в себя развитие способности к взаимодействию, а также опыт разрешения ситуаций по примирению.

Иными словами, модульная вариативность профессиональной подготовки на уровне государственного образовательного стандарта при внедрении факультативного курса «Основы медиации», с одной стороны, обеспечивает углубление знаний о медиации как составляющей готовности к профессиональной деятельности. А с другой стороны - интегрирует когнитивный, эмоционально-оценочный и побудительный компоненты готовности к профессиональной деятельности в области медиации. Присвоение же профессиональной роли медиатора происходит за счет диалогизации и интеракции процесса медиативной подготовки, а также демонстрации способов субъектного взаимодействия в процессе медиации на практике.

Экспериментальная проверка выдвинутой идеи и положений, а также апробация предложенной Программы факультатива «Основы медиации» (72 часа) организована на базе Института социально-гуманитарных технологий и коммуникации БФУ им. И. Канта, Педагогического института БФУ им. И. Канта и Калининградского областного педагогиче- 
ского института в 2014-2017 гг. При разработке программы факультатива «Основы медиации» мы опирались на пятиступенчатую модель Х. Бесемера [24, c. 69-71], которая является модифицированной версией модели американского Института медиации, ввиду ее наглядности, относительной простоты и универсальности, а также на следующие формы (подходы к) медиации: медиация, ориентированная на решение проблем (problem-solving or settlementdirected approach), трансформативная медиация (transformative approach), экосистемная или семейноориентированная медиация (ecosystem or familyfocused approach), медиация, основанная на понимании (understanding-based approach). В результате освоения данной программы у студента должна сформироваться профессиональная компетенция, включающая в себя способность и готовность управлять коммуникацией, регулировать взаимодействие сторон, достигать взаимопонимания между сторонами в процессе медиационной сессии с учетом определения и регулирования эмоциональных проявлений сторон. Как видно из определения, данная профессиональная компетенция не является специфичной для какого-либо отдельного направления и присуща профессионалам как в области психологии, так и журналистики, лингвистики и педагогики.

В ходе эмпирического исследования были использованы следующие методы: анкетирование, опpoc, наблюдение, беседа. Для выявления результативности программы факультатива «Психология медиации» нами были разработаны диагностическая методика на выявление психологической готовности к профессиональной деятельности медиатора, анкета и карта наблюдения. Математическая обработка данных проведена с использованием U-критерий МаннаУитни. Выборка составила 114 респондентов - студентов очной и заочной форм обучения Калининградского областного педагогического института, БФУ им. И. Канта следующих направлений подготовки: «Психология», «Клиническая психология», «Социальная работа», «Лингвистика», мужчин и женщин в возрасте от 18 до 24 лет.

Экспериментальная проверка установила, что готовность к деятельности медиатора после освоения разработанной программы достоверно выше, чем до обучения (см. рис. 1). У студентов зафиксирован существенный сдвиг в объеме знаний, характере понимания, способности к анализу, синтезу информации о процессе медиации, способности к распознаванию и прогнозированию эмоциональных состояний участников процесса медиации. В целом, сформирована способность к оценке значимости и ценности медиации для конкретной цели, ценностная ориентация на антирепрессивный характер взаимодействия и соучастие в процессе примирения, а также мотивация к взаимодействию в процессе разрешения обучающих ситуаций по примирению. Особенно отличаются оценки по когнитивной и конативной составляющей готовности, что свидетельствует о том, что в результате пройденного обучения студенты имеют представление об особенностях медиации, ее психологических и правовых аспектах, а также имеют мотивацию к деятельности медиатором. Также было выявлено, что профессиональная компетентность
Готовность к медиации как компетенция бакалавров..

медиатора у студентов выше после освоения программы, чем до обучения по всем трем ее составляющим, то есть разработанная программа факультатива «Основы медиации» формирует профессиональные компетенции у обучавшихся.

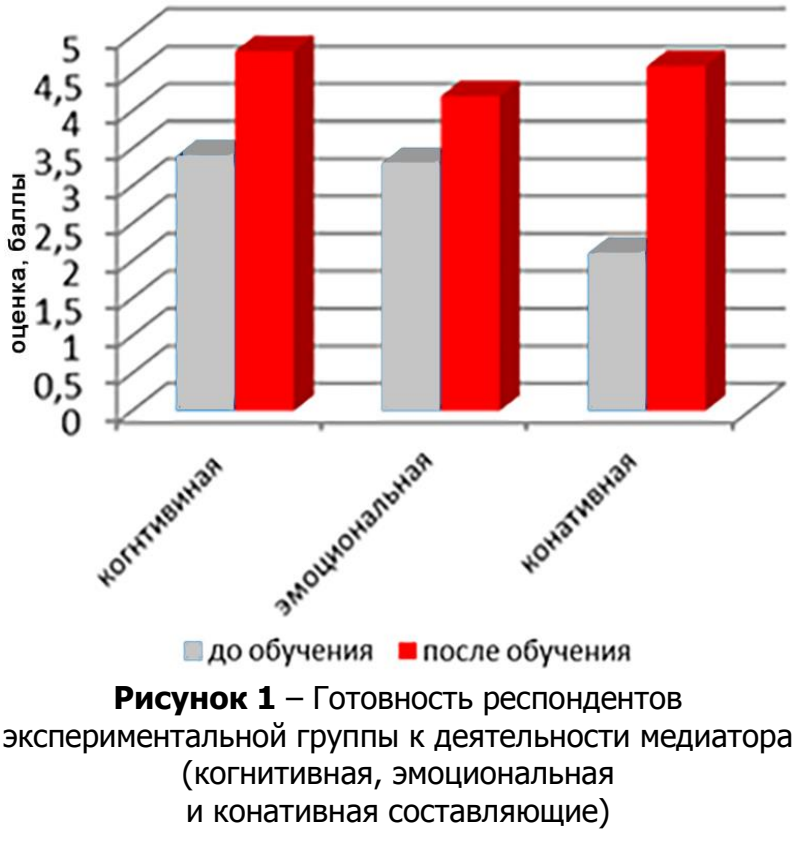

Математическая обработка полученных данных выявила достоверные различия по когнитивной, эмоциональной, конативной составляющим готовности к профессиональной деятельности медиатора, а также достоверные различия по следующим психологическим профессиональным компетенциям: 1) способность и готовность управлять коммуникацией, регулировать взаимодействие сторон в процессе медиации; 2) способность и готовность правильно определять и регулировать эмоциональные проявления сторон; 3) способность и готовность обеспечить взаимопонимание между сторонами $\left(\mathrm{U}_{\text {эмп }} \leq \mathrm{U}_{0,05}\right)$.

Результаты эксперимента позволяют заключить, что предложенная программа и методика компетентностного моделирования готовности к медиации слушателей факультатива на основе компетентностного подхода, теории аттитюда и идей восстановительного способа реагирования на конфликтные и криминальные ситуации позволят сформировать у студентов компетенцию «Способность и готовность к медиации». Полученные результаты открывают широкие перспективы для подготовки медиаторов в процессе как основного (модульного, факультативного), так и дополнительного профессионального образования студентов гуманитарных и образовательных направлений подготовки, а также перспективы более широкого распространения профессиональной медиации в разных сферах профессиональной деятельности.

\section{Список литературы:}

1. Шамликашвили Ц.А., Харитонов С.В. Основания медиации (Медиация как область научных исследований // Вестник федерального института медиации. 2017. № 1. С. 30-50.

2. Бодрова Е.А. Медиация как способ защиты прав и интересов лиц, не достигших совершенноле- 
тия // Черные дыры в российском законодательстве. 2014. № 4. C. 52-54.

3. Солдатова Г.У., Рассказова Е.И. Безопасность подростков в Интернете: риски, совладание и родительская медиация // Национальный психологический журнал. 2014. № 3 (15). С. 36-48.

4. Осипов Г.В., Онипченко О.Г. Медиация как способ профилактики суицидального поведения в школе // Open innovation: сб. статей II междунар. науч.-практ. конф. В 2-х частях. Пенза: Наука и просвещение, 2017. С. 221-224.

5. Качер О.В. Семейная медиация и работа органов опеки и попечительства // Семейная медиация в ювенальной политике: сб. статей междунар. науч.практ. конф. / отв. редактор: В.Ю. Сморгунова. СПб.: Российский государственный педагогический университет им. А.И. Герцена, 2014. С. 105-107.

6. Пантелеева И.А. Семейная медиация как альтернативная процедура разрешения споров // Вестник Нижегородского университета им. Н.И. Лобачевского. 2014. № 1-2. С. 452-457.

7. Ефимова И.Ю. Медиация в трудовых спорах и ее применение // Вестник образовательного консорциума. Среднерусский университет. Серия: Гуманитарные науки. 2014. № 3. С. 18-218.

8. Дмитрикова Л.В. Медиация этнических конфликтов в образовании // Глобализация науки: проблемы и перспективы: сб. статей междунар. науч.практ. конф. Уфа: Аэтерна, 2014. С. 219-221.

9. Самсонова Н.В. Конфликтология и медиация в образовании: этап стандартизации // Конфликтология. 2014. № S. С. 59-63.

10. Статеева Е.В. Перевод и коммуникативная языковая медиация как навыки устного общения // Ученые записки Международного банковского института. 2014. № 8-1. С. 141-146.

11. Шебалов Р.Ю., Кристал Д. Языковая игра и лингвистическая медиация // Лингвистика креатива 3 / под общ. ред. Т.А. Гридиной. Екатеринбург, 2014. C. $89-114$.

12. Даровских Ю.В. Медиация в механизме управления социальными процессами // Академический вестник. 2014. № 4 (30). С. 170-177.

13. Вьюшков Э.С., Бады-Сагаан Р.А., Пичугина Т.В., Кондратьева К.С. Медиация в системе урегулирования межнациональных конфликтов и противодействия экстремизму // Экономика и социум. 2014. № 4-2 (13). C. 284-288.

\section{MEDITATION READINESS AS A HUMANITIES BACHELOR STUDENTS' COMPETENCE} (C) 2018

\author{
Budarina Anna Olegovna, doctor of pedagogical sciences, professor, director of Education Institute \\ Simaeva Irina Nikolaevna, doctor of psychological sciences, professor of Humanities Institute \\ Chupris Alina Sergeevna, postgraduate student of Education Institute \\ Shakhtorina Ekaterina Valentinovna, candidate of pedagogical sciences, \\ associate professor of Humanities Institute \\ Immanuel Kant Baltic Federal University (Kaliningrad, Russian Federation)
}

14. Гайдук В.В., Лукьянцев А.С. Политическая медиация как новая политическая технология // Вопросы политологии. 2014. № 4 (16). С. 81-91.

15. Костина О.В., Костин А.А. Урегулирование (медиация) во внешнеэкономической деяUniversum: экономика и юриспруденция. 2015. 2 (13). С. 5

16. Иванова Е.В. Медиация как междисципли-

17. Брукс Д., Йен М. Различия между медиацией и восстановительным правосудием/практикой // Вестник восстановительной юстиции. 2016. № 13. 18. Чуприс А.С. Модели медиации в условиях образовательных учреждений // Вестник Балтийского федерального университета им. И. Канта. Серия: Филология, педагогика, психология. 2016. № 2.

19. Профессиональный стандарт: Специалист в области медиации (медиатор). Утвержден Министерством труда и социальной защиты Российской Федерации от 15 декабря 2014 г. № 1041н [Электронный ресурс]. - Бюллетень нормативных актов федеральных органов исполнительной власти. № 30. 27.07.2015.

20. Зимняя И.А. Ключевые компетенции - новая парадигма результата современного образования // Интернет-журнал «Эйдос». 2006. 5 мая.

21. Симаева И.Н., Чуприс А.С. Компетентностная зования: история и задачи // Вестник Балтийского федерального университета им. И. Канта. Серия:

22. Хуторской А.В. Ключевые компетенции и образовательные стандарты // Интернет-журнал «Эйос». 2002. 23 апреля.

23. Бударина А.О., Чуприс А.С. Готовность к мес студентов гуманитарных направлений // Образвитии современного общества: V междунар. науч.-практ. конф. Ставрополь: АНО ВО СКСИ, 24. Бесемер Х. Медиация. Посредничество в конфликтах. Калуга: Духовное познание, 2005. 176 с. 
tarian interpretation of the mediator as a mediator in the settlement of disputes and conflicts, the diluted requirements of the professional standard for higher education of the mediator and the inability to use human resources among the BA graduates for mediation. It is proposed to introduce the universal competence «Ability and readiness for mediation» into the GEF3++ vocational training for Humanities and Education students. The paper considers the structure of this competence and the content of the cognitive, emotional-evaluative and motivational components of readiness for professional activity in the field of mediation. The paper also contains the results of the approbation of the elective module «Fundamentals of Mediation» and techniques of modeling the readiness for mediation on the basis of the competence approach, the theory of attitudes and ideas of a restorative strategy of responding to conflict and criminal situations.

Keywords: mediation; humanitarian worldview; untirepressive philosophy and methodology of mediation; social unrest decrease; socio-humanitarian practices; professional standard of mediator; competency-based approach; competence; mediation readiness; additional professional education; bachelor's competence ability; humanities.

УДК 378.14

Статья поступила в редакцию 10.03.2018

\title{
РАЗВИТИЕ ИКТ-КОМПЕТЕНТНОСТИ БУДУЩИХ УЧИТЕЛЕЙ ИНФОРМАТИКИ В ПРОЦЕССЕ ИЗУЧЕНИЯ РОБОТОТЕХНИКИ
}

(C) 2018

\author{
Бужинская Надежда Владимировна, кандидат педагогических наук, \\ доцент кафедры информационных технологий \\ Гребнева Дарья Михайловна, кандидат педагогических наук, \\ доцент кафедры информационных технологий \\ Нижнетагильский государственный сочиально-педагогический институт (филиал) \\ Российского государственного профессионально-педагогического университета \\ (2. Нижний Тагил, Свердловская область, Российская Федераџия)
}

\begin{abstract}
Аннотащия. Статья посвящена проблеме развития информационно-коммуникационной компетентности будущих учителей информатики как важнейшей составляющей профессиональной компетентности учителя. Актуальность развития ИКТ-компетентности учителя в области робототехники определяется внедрением данного предмета в школу, что требует соответствующей подготовки педагогических кадров. Целью статьи является представить эффективные методы и приемы развития ИКТ-компетентности в процессе изучения образовательной робототехники студентами педагогических вузов. На основе анализа нормативных документов, определяющих требования государства, общества и работодателей к подготовке учителя авторы определяют общую структуру ИКТ-компетентности учителя, которая положена ими в основу разработки содержания и методики преподавания образовательной робототехники в вузе. Предложены методы и приемы формирования основных компонентов ИКТ-компетентности будущих учителей в процессе изучения робототехники. Для каждого компонента ИКТ-компетентности на занятиях по образовательной робототехнике приведены примеры заданий и критерии их оценки. Совокупность оценок по каждому из компонентов позволит сделать вывод об уровне ИКТ-компетентности студентов и при необходимости внести коррективы в предлагаемую методику. Представленные материалы могут быть использованы в педагогической деятельности преподавателей педагогических вузов направления «Педагогическое образование» профилей обучения «Информатика и ИКТ», «Физика и информатика», «Информатика и математика».

Ключевые слова: информационно-коммуникационные технологии; информатизация; ИКТ-компетентность; мотивационно-ценностные ориентации; мотив; рефлексия; рефлексивные умения; саморазвитие; самосовершенствование; готовность; опыт деятельности; робототехника; образовательная робототехника; робот; конструкция; программа управления; алгоритм.
\end{abstract}

В условиях развития информационно-коммуникационных технологий учащиеся способны самостоятельно получать знания из различных источников (интернета, средств массовой информации и др.). В связи с этим роль учителя как транслятора знаний во многом заменяется ролью организатора и наставника деятельности обучающихся. Информатизация образования создает дополнительные возможности для становления личности будущего учителя.

Результаты подготовки студентов в вузе в области информационно-коммуникационных технологий характеризуются с помощью ИКТ-компетентности, под которой понимается вид педагогической компетентности, позволяющей эффективно осуществлять профессионально-педагогическую деятельность с использованием информационно-коммуникационных технологий $[1$, с. 8]. Нормативные требования к про- фессиональной ИКТ-компетентности учителя представлены в Едином квалификационном справочнике должностей работников образования, Ф3 № 273 «Об образовании в Российской Федерации», федеральных государственных образовательных стандартах общего образования (ФГОС). Общая структура ИКТкомпетентности учителя представлена на рис. 1.

Знания, умения и навыки, входящие в состав ИКТ-компетентности, начинают формироваться в школьном возрасте, а развиваются в процессе обучения в вузе. Совершенствование в данной области происходит на протяжении всей деятельности специалиста за счет приобретения жизненного и профессионального опыта. Рассмотрим особенности формирования основных компонентов ИКТ-компетентности будущих учителей на примере изучения робототехники. 